\title{
A Novel Approach to Determine the Mixing Time in a Water Model of an AOD Converter
}

\author{
Christian WUPPERMANN, ${ }^{1) *}$ Nils GIESSELMANN, ${ }^{1)}$ Antje RÜCKERT, ${ }^{1)}$ Herbert PFEIFER, ${ }^{1)}$ \\ Hans-Jürgen ODENTHAL ${ }^{2)}$ and Erich HOVESTÄDT ${ }^{2)}$
}

1) RWTH Aachen University, Department for Industrial Furnaces and Heat Engineering, Kopernikusstraße 10, Aachen, 52074 Germany. E-mail: giesselmann@iob.rwth-aachen.de, arueckert@iob.rwth-aachen.de,pfeifer@iob.rwth-aachen.de 2) SMS Siemag AG, Eduard-Schloemann-Str. 4, Düsseldorf, 40237 Germany. E-mail: hans-juergen.odenthal@sms-siemag.com, erich.hovestaedt@sms-siemag.com

(Received on April 17, 2012; accepted on May 23, 2012)

\begin{abstract}
During the argon-oxygen-decarburization (AOD) process high-chromium steel melts are decarburized by oxygen and inert gas injection through sidewall tuyeres and a top-lance. The tap-to-tap time of the AOD process depends mainly on the time which is necessary to produce a homogeneous distribution of all required components in the melt. This mixing time is correlated to the process time. Shorter tapping times lead to a higher productivity, lower energy consumption and lower operating costs. Prior to the reduction stage, the mixing behavior influences the melting of the solid slag layer after the addition of ferro-silicon. Fast and efficient melting of the solid slag compounds is essential to attain sufficient reduction rates. Conventional approaches to experimentally investigate the mixing efficiency in aqueous models (e.g. the 95\%-mixing time criterion), yield results which show a large variance concerning the mixing time for a single operating point. In the present study a novel approach for the determination of the mixing time in a water model of an AOD converter is presented and verified. The results show a lower variance and an increased reproducibility as compared to the prior measurement technique. Using these experimental results, the vessel shape and the required volume flow rate of the AOD process gas can be optimized. Furthermore, numerical simulations can be validated using the presented results. The measurement technique can be utilized in water models representing other metallurgical processes.
\end{abstract}

KEY WORDS: AOD process; mixing time; water modeling; PIV measurement.

\section{Introduction}

During the last four decades the AOD process has been established as a reliable and efficient refining process in stainless steelmaking. Compared to other injection geometries, e.g. bottom blowing, the injection of process gases (oxygen, nitrogen, argon) through sidewall tuyeres shows advantages in mixing effectiveness. ${ }^{1)}$ The momentum of the gas jets is absorbed within a short distance from the tuyere exit, due to the large density difference between steel and gas. The buoyancy force acting on the gas phase changes the jet's trajectory into a vertical bubble column (plume). The drag force between gas and melt leads to the characteristic AOD flow pattern described by various authors. ${ }^{2-6)}$ Thus, the stirring energy of the argon bubbles, which are predominant during the AOD reduction process stage, is introduced into the melt. The process variables, which determine the stirring effect for a given multiphase system, are the vessel and tuyere geometry, the number of tuyeres, the angle between the tuyeres, the melt capacity and the volume flow rate. Increased stirring leads to shorter mixing times, more efficient slag melting during reduction stage, and an increase

* Corresponding author: E-mail: wuppermann@iob.rwth-aachen.de DOI: http://dx.doi.org/10.2355/isijinternational.52.1817 in productivity, but also to higher vessel oscillations.

Wei and his coworkers ${ }^{7-10)}$ carried out several water model studies on the influence of different tuyere geometries (annular tube type with and without spiral flat), the angle between the tuyeres, the number of tuyeres and the volume flow rate on mixing time. Furthermore, they calculated the stirring energy transferred to the liquid phase by the gas jets and the bubble column. Wei obtained a dimensionless correlation between the reciprocal Strouhal number and the modified Froude number.

Ternstedt et al. ${ }^{11)}$ investigate the mixing time in two different water models of an AOD converter. The authors vary the volume flow rate, the bath height and the vessels' diameter. The dimensionless correlation which is used in this study is a relation between the reciprocal Strouhal number and, contrary to Wei et al., the Reynolds number. Fabritius et $a l .{ }^{12)}$ performed a physical modeling study on a 1:7 scale water model. They analyzed the mixing time and the mixing power as a function of volume flow rate.

All studies have in common, that salt solutions are used as tracer and subsequently conductivity measurements are carried out to determine the mixing time. The entire amount of the tracer is injected into the water as a single pulse. The mixing time of the typical response function is defined as 
the time when the response signal reaches $95 \%$ and $98 \%$, respectively of the final mixing concentration. The use of a salt solution and the related local density differences in the water cause convection, which is suspected to superimpose and change the flow field. ${ }^{13)}$ In order to prevent these interferences, food coloring is used as a tracer in the present study. The difference between the densities of the food coloring and water are within a range of $\pm 1 \%$. Regarding reproducibility, the measurement technique leads to a relatively high variance of the determined mixing times. ${ }^{8,9)}$ $\mathrm{Wei}^{8)}$ performed up to four measurements per parameter. The ratio between the standard deviation of the measurements and the average mixing time for one parameter is equal to values up to $20 \%{ }^{8}{ }^{8}$ To obtain reliable statistical results, many trials per investigated point are necessary.

In this study a new approach to determine the mixing time in water models is presented. Contrary to the described literature, the tracer is injected continuously into the system. The distribution of the tracer is detected by a photometer, which measures the absorbance of the fluid passing the probe volume. Bouchard et al. ${ }^{14)}$ use a similar method to determine the residence time distribution curves in a water model of a twin roll strip caster. The analysis of the response function allows a reliable evaluation of the mixing time. The variance of the analyzed mixing time is reduced. The aim of the present study is to determine the mixing time for different fill levels and volume flow rates. The investigated pairs of fill levels and flow rates are defined as operating points. A presentation in terms of dimensionless numbers enables a transfer of the results to other water model geometries, as well as industrial scale AOD converters. Furthermore, operating points with a short mixing time can be identified, that can be used to optimize the AOD process.

\section{Physical Simulation}

\subsection{Experimental Setup}

Figures 1 and 2 show the experimental setup used for the determination of the mixing time. The 1:4 scale vessel is made of acrylic glass. The geometry is based on the required

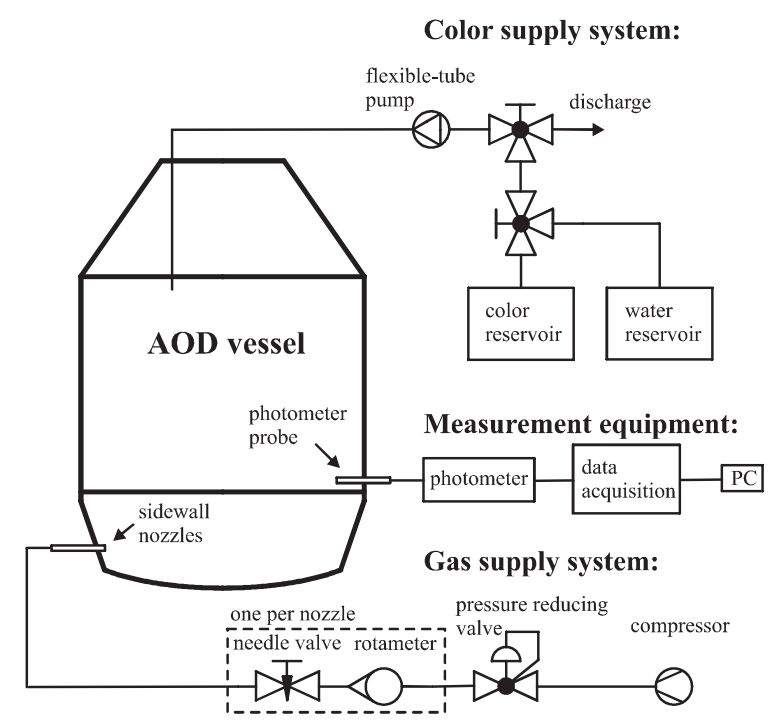

Fig. 1. Gas supply system and measurement setup for the AOD water model system. geometric similarity to an 120 ton AOD-converter. The seven sidewall tuyeres are arranged in a horizontal plane. They are adjusted radially towards the centerline at an angle of $\alpha_{\mathrm{n}}=18^{\circ}$ between each tuyere, as sketched in Fig. 3. A compressor followed by a pressure-reducing valve provides a constant volume flow rate of the air. The volume flow rate can be controlled by a flow meter, whereby each tuyere is equipped with a metering valve. A blue, concentrated and water-soluble food coloring is used. The maximum of the absorbance spectrum is located at a wavelength of $\lambda_{\text {coloring }}=$ $630 \mathrm{~nm}$. The food coloring is injected into the system by a flexible-tube pump, which provides a constant volume flow rate of tracer liquid over the measurement time. The vessel geometry and process data is presented in Table 1. A photometer is used to measure the absorbance of the fluid flowing through the probe volume using a photosensitive cell. The analyzed wavelength is adjustable and is set in this case to $\lambda_{\text {coloring }}=630 \mathrm{~nm}$. A beam of light with a predefined intensity is conducted by a fiber-optic cable. After exiting the fiber-optic, the light shines through the probe volume. After a distance of $10 \mathrm{~mm}$, a mirror reflects the light. After the secondary passage through the probe volume the light is conducted by a second fiber-optic cable to a photosensitive cell. By comparing the intensity of the initial to the reflected

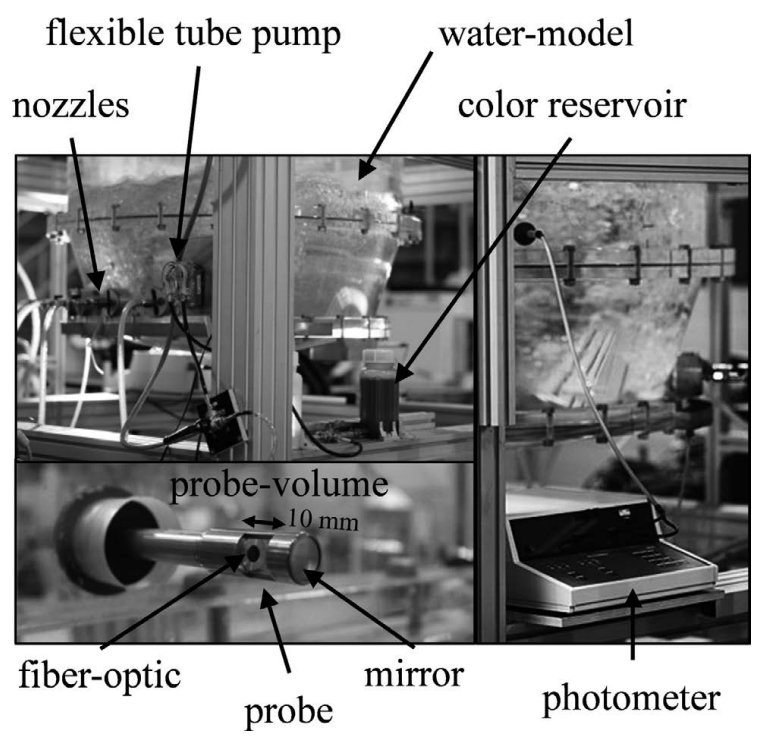

Fig. 2. Food coloring injection and photometer setup for the AOD water model.

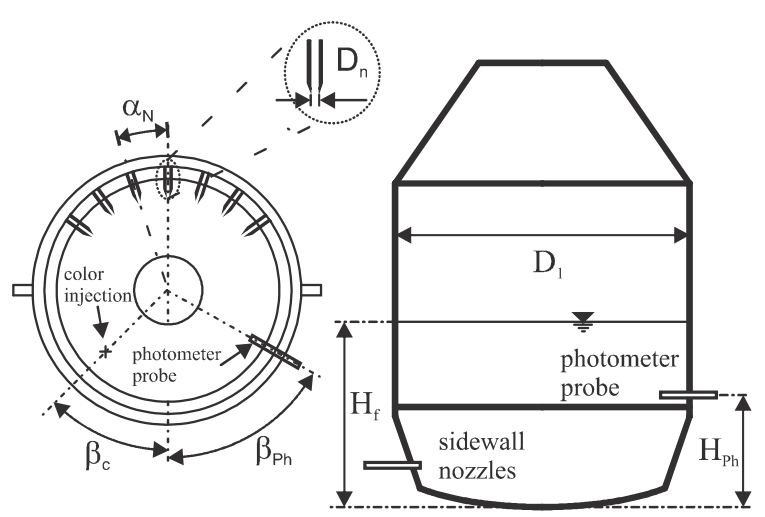

Fig. 3. Schematic sketch of the water model geometry and measurement setup. 
Table 1. Geometry and process data of the water model.

\begin{tabular}{|c|c|c|c|}
\hline & Symbol & Value & Unit \\
\hline Inner diameter (cylinder) & $\mathrm{D}_{1}$ & 0.931 & $\mathrm{~m}$ \\
\hline Liquid level (design point) & $\mathrm{H}_{\mathrm{f}}$ & 0.524 & $\mathrm{~m}$ \\
\hline Diameter of the sidewall tuyeres & $D_{n}$ & 0.002 & $\mathrm{~m}$ \\
\hline Angle between sidewall tuyeres & $\alpha_{\mathrm{n}}$ & 18 & degree \\
\hline $\begin{array}{l}\text { Angle between symmetry line } \\
\text { and food coloring injection }\end{array}$ & $\beta_{\mathrm{c}}$ & 45 & degree \\
\hline $\begin{array}{l}\text { Angle between symmetry line } \\
\text { and photometer probe }\end{array}$ & $\beta_{\mathrm{Ph}}$ & 60 & degree \\
\hline $\begin{array}{l}\text { Height of the } \\
\text { photometer probe }\end{array}$ & $\mathrm{H}_{\mathrm{Ph}}$ & 0.4 & $\mathrm{~m}$ \\
\hline Liquid density & $\rho_{1}$ & 998 & $\mathrm{~kg} / \mathrm{m}^{3}$ \\
\hline Gas density (STP) & $\rho_{\mathrm{g}}$ & 1.293 & $\mathrm{~kg} / \mathrm{m}^{3}$ \\
\hline $\begin{array}{l}\text { Volumetric flow rate } \\
\text { of the food coloring }\end{array}$ & $\dot{\mathrm{V}}_{\text {color }}$ & $\sim 200$ & $\mathrm{ml} / \mathrm{min}$ \\
\hline
\end{tabular}

light, the photometer converts the signal into an electric current, which is proportional to the absorbance. A calibration procedure has been carried out to obtain the relation between measured absorbance and the concentration of the coloring. The positions of the coloring injection point and the probe are sketched in Fig. 3. The distance between the point of detection and the vessel wall is set to $70 \mathrm{~mm}$. The measurement data is logged by a data acquisition system and a PC. The measurement frequency is set to $5 \mathrm{~Hz}$.

The Particle-Image-Velocimetry (PIV) is used to visualize the two-dimensional velocity field in the symmetry plane of the water-model. The PIV system consists of a Nd-YAG Laser with a pulse energy of $\mathrm{E}_{\mathrm{L}}=200 \mathrm{~mJ}$ and a wavelength of $\lambda_{\mathrm{L}}=532 \mathrm{~nm}$. A light sheet optic is used to illuminate a plane in the water model, where the flow pattern is to be analyzed. Two CCD cameras with a resolution of $2000 \times$ 2000 pixels record the images of the particle patterns in the plane. These two cameras enlarge the optical accessibility of the water model, in order to visualize the whole flow profile in the symmetry plane at once. When the light-sheet reaches the bubble columns, a large portion of the light is scattered at the phase boundary between water and air. Filters with a cut-off wavelength of $\lambda_{\text {cut-off }}<540 \mathrm{~nm}$ are used to avoid the exposure of the sensitive camera chips to the scattered light. Polyamide particles doped with Rhodamine B are used as tracer for the PIV measurements. The maximum of the fluorescence spectrum of Rhodamine $B$ is in the range of $\lambda_{\text {Rhodamine }}=584 \mathrm{~nm}$, which is $>\lambda_{\text {cut-off. }}$ Thus, only the fluorescence wavelength of the particles passes the filters and subsequently, the pictures show the particle patterns without the disturbance of the scattered light. The experimental setup for the PIV measurements is shown in Fig. 4. The technical data of the PIV facility is given in Table 2.

\subsection{Evaluation of Mixing Time for Continuous Tracer Injection}

The food coloring injection and the data logging system are started, after the flow field in the AOD vessel has reached a quasi-stationary state. Figure $\mathbf{5}$ shows a typical plot of the measured photometer signal with respect to the measurement time. It takes several seconds before the first bulk of coloring reaches the probe and subsequently the

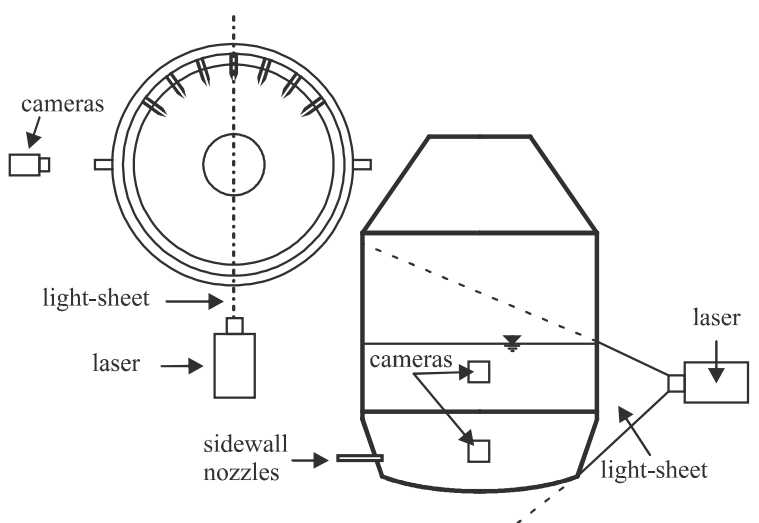

Fig. 4. Schematic sketch of PIV measurement setup used to determine the flow pattern in the symmetry plane of the $1: 4$ scale water model.

Table 2. Technical data of the PIV facility.

\begin{tabular}{ccccc}
\hline & & Symbol & Value & Unit \\
\hline Nd-YAG-Laser & wavelength & $\lambda_{\mathrm{L}}$ & 532 & $\mathrm{~nm}$ \\
& pulse energy & $\mathrm{E}_{\mathrm{L}}$ & 200 & $\mathrm{~mJ}$ \\
& thickness of lightsheet & $\mathrm{d}_{\mathrm{LS}}$ & $<1$ & $\mathrm{~mm}$ \\
\hline CCD cameras & resolution & & $2000 \times 2000$ & $\mathrm{px}$ \\
\hline Filter & cut-off wavelength & $\lambda_{\text {cut-off }}$ & 540 & $\mathrm{~nm}$ \\
\hline Tracer particles & diameter & $\mathrm{d}_{\mathrm{P}}$ & 100 & $\mu \mathrm{m}$ \\
& & $\rho_{\mathrm{P}}$ & 1016 & $\mathrm{~kg} / \mathrm{m}^{3}$ \\
& & $\lambda_{\text {Rhodamine }}$ & 584 & $\mathrm{~nm}$ \\
\hline
\end{tabular}

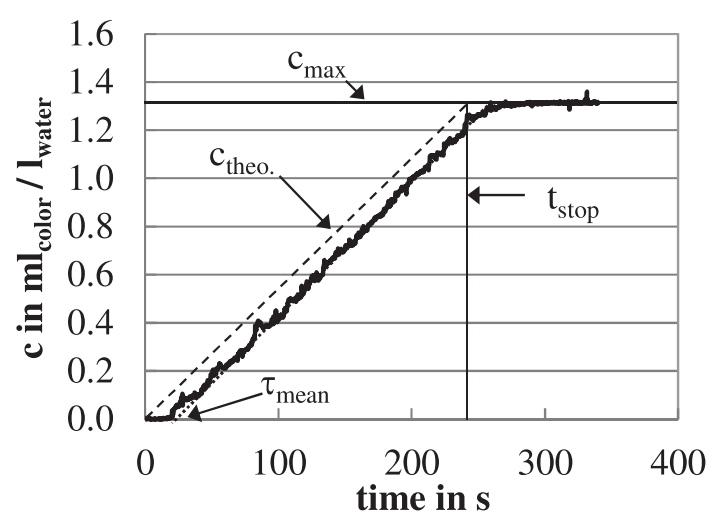

Fig. 5. Measured coloring concentration vs. time to determine the mixing time $\tau_{\text {mean }}$ in the 1:4 scale water model (continuous injection of the tracer).

photometer measures values beyond $\mathrm{c}=0 \mathrm{ml}_{\mathrm{color}} / \mathrm{l}_{\text {water }}$. After this time delay, the slope of the concentration curve increases until it remains almost constant. After the color injection is stopped, the concentration further rises up to a final and constant concentration $\mathrm{c}_{\max }$. The corresponding time $\mathrm{t}_{\text {stop }}$ has to be logged. The entire measurement ends after the signal reaches $c_{\max }$. The measured data is analyzed as follows as sketched in Fig. 6:

The range of the plot used for the determination of the mixing time is the linear part (cf. Fig. 6, lower boundary < $\mathrm{t}<$ upper boundary). The upper boundary of the linear part is given by $t_{\text {stop. }}$. When the slope of the signal reaches the linear range, the corresponding time is defined as the lower 
lower boundary upper boundary $=\mathrm{t}_{\text {stop }}$

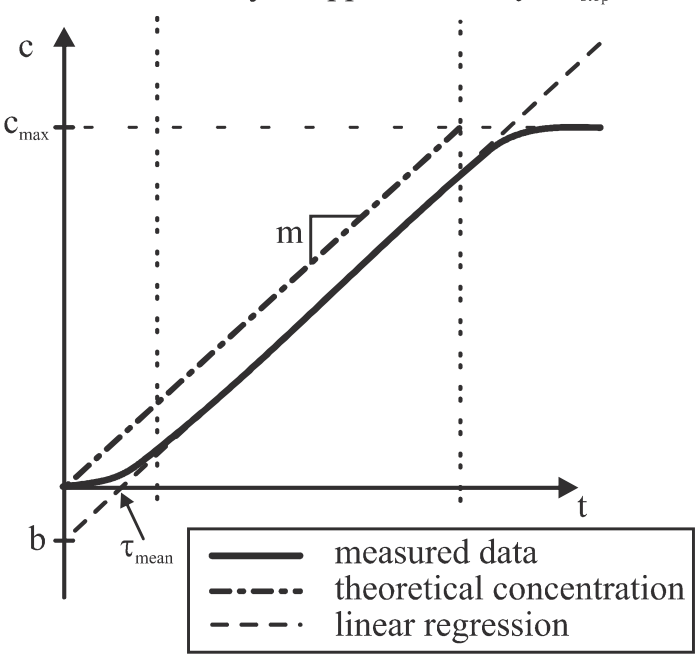

Fig. 6. Methodology for the determination of the average mixing time $\tau_{\text {mean }}$ in the AOD water model

boundary. The dash-dotted line in Fig. 6 represents the theoretical color concentration $\mathrm{c}_{\text {theo }}$ assuming an instantaneous, complete mixing. A linear regression analysis is performed in order to obtain a mathematical description of the measured data. A linear function shown in Eq. (1) is used to approximate the linear part of the data.

$$
\mathrm{c}=\mathrm{m} \cdot \mathrm{t}+\mathrm{b}
$$

c Concentration of food coloring in $\mathrm{ml}_{\text {color }} / \mathrm{l}_{\text {water }}$

$\mathrm{m} \quad$ Slope of the plot in $\mathrm{ml}_{\text {color }} /\left(1_{\text {water }} \mathrm{s}\right)$

$\mathrm{t}$ Measurement time in $\mathrm{s}$

b y-axis intercept in $\mathrm{ml}_{\text {color }} / 1_{\text {water }}$

The slopes of both curves, theoretical and measured concentration versus time, are assumed to be equal. Thus the slope $\mathrm{m}$ can be calculated as follows.

$$
\mathrm{m}=\frac{\mathrm{c}_{\max }}{\mathrm{t}_{\text {stop }}}
$$

$\mathrm{c}_{\max }$ Measured concentration after complete mixing in $\mathrm{ml}_{\text {color }} / \mathrm{l}_{\text {water }}$

$t_{\text {stop }}$ Time when coloring injection is stopped in $\mathrm{s}$

The $y$-axis intercept $b$ is calculated by the linear regression of the measured data:

$$
\mathrm{b}=\frac{1}{\mathrm{~N}} \sum_{\mathrm{i}=1}^{\mathrm{N}} \mathrm{c}_{\mathrm{i}}-\mathrm{m} \cdot \frac{1}{\mathrm{~N}} \sum_{\mathrm{i}=1}^{\mathrm{N}} \mathrm{t}_{\mathrm{i}}
$$

$\mathrm{N} \quad$ Number of measured concentrations values over time

$\mathrm{c}_{\mathrm{i}} \quad$ Measured concentration in $\mathrm{ml}$ color $/ \mathrm{l}_{\text {water }}$

$\mathrm{t}_{\mathrm{i}} \quad$ Time corresponding to the concentration $\mathrm{c}_{\mathrm{i}}$ in $\mathrm{s}$

The mixing time $\tau_{\text {mean }}$ is now to be defined as the zero ( $\mathrm{x}$ axis intercept) of Eq. (1) and is shown in Eq. (4). The mathematical definition of $\tau_{\text {mean }}$ can also be interpreted as the average temporal distance between the graphs of the theoretical concentration $c_{\text {theo. }}$ and the graph of the approximated measurement data (linear part between lower and upper boundary) shown in Fig. 6 . This is intention of defining $\tau_{\text {mean }}$

\begin{tabular}{|c|c|c|c|}
\hline & Symbol & Value & Unit \\
\hline Minimum volume flow rate & $\dot{\mathrm{V}}_{\text {min }}$ & $4.88 \cdot 10^{-4}$ & $\mathrm{~m}_{\text {(STP) }}^{3} / \mathrm{S}$ \\
\hline Minimum Froude number & $\mathrm{Fr}_{\mathrm{m}, \min }$ & 550 & - \\
\hline Maximum volume flow rate & $\dot{\mathrm{V}} \max$ & $8.37 \cdot 10^{-4}$ & $\mathrm{~m}_{(\mathrm{STP})}^{3} / \mathrm{S}$ \\
\hline Maximum Froude number & $\mathrm{Fr}_{\mathrm{m}, \max }$ & 1482 & - \\
\hline Minimum height to diameter ratio & $\mathrm{H}_{\mathrm{f}, \min } / \mathrm{D}_{1}$ & 0.46 & - \\
\hline Maximum height to diameter ratio & $\mathrm{H}_{\mathrm{f}, \max } / \mathrm{D}_{1}$ & 0.79 & - \\
\hline
\end{tabular}
in the present paper.
Table 3. Operating range for the mixing time measurements.

$\tau_{\text {mean }}$ Average mixing time in $\mathrm{s}$

The distance between the point of coloring injection and the photometer probe should be large enough in order to ensure that the plots of the theoretical and the measured concentrations do not intersect each other. Otherwise the presented experimental technique would not be applicable.

\subsection{Similarity Considerations and Measurement Pro- gram}

The investigated parameters in the present study are volume flow rate $\dot{V}$ and fill level $\mathrm{H}_{\mathrm{f}}$. The parameters have to be considered in their dimensionless form to enable a transfer to other water models or AOD converter geometries. The movement of the gas plume depends on the equilibrium of buoyancy, gravity, and inertia forces. Therefore, the jet injection is characterized by the modified Froude number, which is commonly used in literature as a criterion to reach kinematic similarity between AOD converters, prototypes and water models.

$$
\mathrm{Fr}_{\mathrm{m}}=\frac{\rho_{\mathrm{g}}}{\rho_{\mathrm{l}}} \frac{\mathrm{u}_{\mathrm{g}}^{2}}{\mathrm{~g} \cdot \mathrm{D}_{\mathrm{n}}} \quad\left(\text { for } \rho_{\mathrm{g}}<<\rho_{1}\right)
$$

$\rho_{\mathrm{g}} \quad$ Gas density at the tuyere exit in $\mathrm{kg} / \mathrm{m}^{3}$

$\rho_{1} \quad$ Liquid density in $\mathrm{kg} / \mathrm{m}^{3}$

$\mathrm{u}_{\mathrm{g}} \quad$ Mean gas velocity at the tuyere exit in $\mathrm{m} / \mathrm{s}$

$\mathrm{D}_{\mathrm{n}} \quad$ Tuyere diameter in $\mathrm{m}$

The volume flow rate can be expressed in terms of the Froude number in a dimensionless manner. Gas density and velocity at the tuyere exit have to be calculated in terms of gas dynamics, as the flow in the tuyere exceeds $\mathrm{Ma}>0.3 .{ }^{15}$ ) The fill level is expressed in terms of the ratio between fluid height $\mathrm{H}_{\mathrm{f}}$ and vessel diameter $\mathrm{D}_{1}$. The operating ranges for both parameters are presented in Table 3. As a design of experiment technique Latin Hypercube Sampling ${ }^{16,17)}$ (LHS) is used in order to reach a smooth response contour plot, whereby the statistical reliability of the determined values is also ensured. As a result of these considerations a total number of 55 experiments are performed.

\section{Results and Discussion}

\subsection{Preliminary Tests}

In preliminary tests carried out for the present study mixing time measurements were done in the water model, 
whereby the food coloring was injected as a single pulse. The mixing time $\tau_{95 \%}$ is defined as the time when the response signal reaches $95 \%$ of the final mixing concentration $\mathrm{c}_{\max }$, shown in Fig. 7.

In these preliminary tests $\tau_{95 \%}$ was determined for 8 different fill levels. Each fill level was tested five times. The results of these tests are shown in Fig. 8. They show a variance of up to $60 \%$ in relation to the respective average values for a single fill level. Thus, many measurements per parameter have to be carried out, in order to ensure a statistically reliable value.

One reason for the large deviation of the mixing time using a single tracer pulse is the transient character of the flow field in the water model. Figure 9 shows PIV measurements of the flow field in the symmetry plane of the 1:4 scale model for three different time steps. The flow pattern with randomly distributed vortices leads to a highly stochastic dispersion of the tracer. Qualitative observations during the mixing time experiments also confirm this hypothesis. The time-dependent and spatial dispersion of the tracer is different for each experiment.

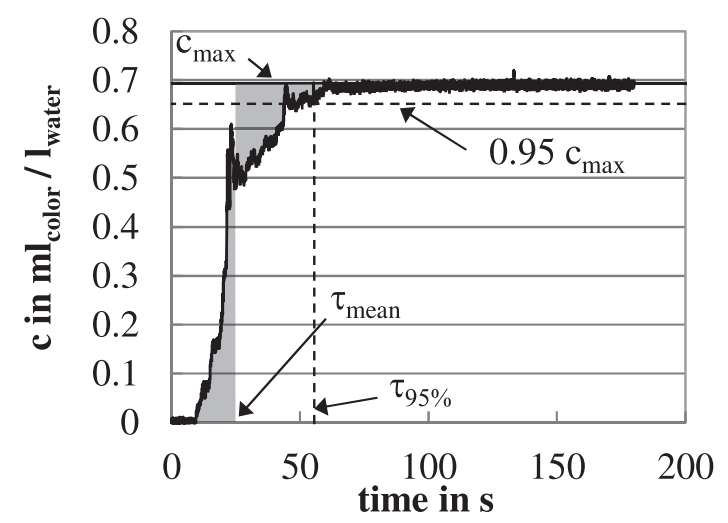

Fig. 7. Measured coloring concentration vs. time to determine the mixing time $\tau_{95 \%}$ in the 1:4 scale water model (preliminary tests; pulse injection of the tracer).
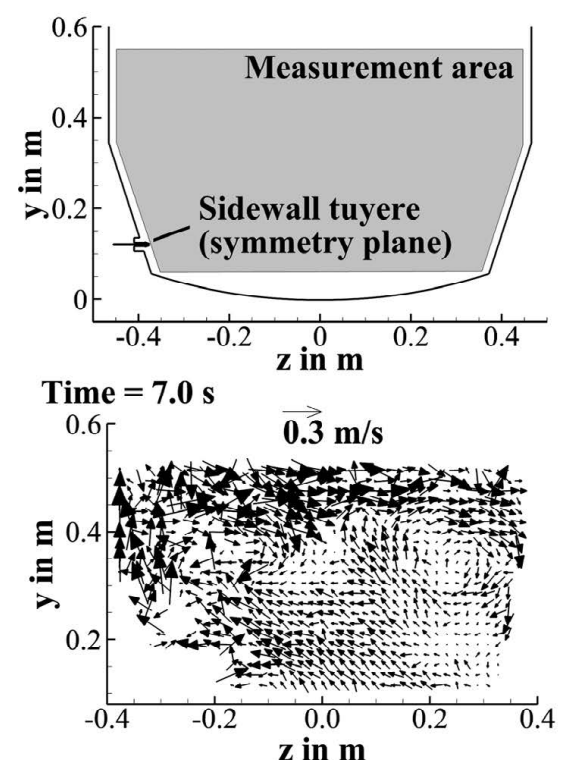

\subsection{Applicability of the Measurement Setup}

In a first step the applicability of the measurement method was tested. Four experiments defining the minima and maxima of the operating range and additionally the design point of the water model were carried out, as sketched in Fig. 10. Five experiments for each of these operating points were performed and evaluated statistically. In order to ensure the comparability of the experiments' variations, the deviations (var) are normalized according to Eq. (6). The average mixing time $\tau_{\text {mean }}$ and the related variances are presented in Fig. 10.

$$
\operatorname{var}=\frac{\sigma}{\tau_{\text {mean }}}
$$

var Variation of the mixing time

$\sigma \quad$ Standard deviation of mixing time in $\mathrm{s}$

Figure 11 shows the raw data of the five tested operating points. The numeration corresponds to the numbers of the operating points in Fig. 10. The variances are in a range of $5.9 \%$ to $8.2 \%$. The mixing times are between $11.3 \mathrm{~s}$ and

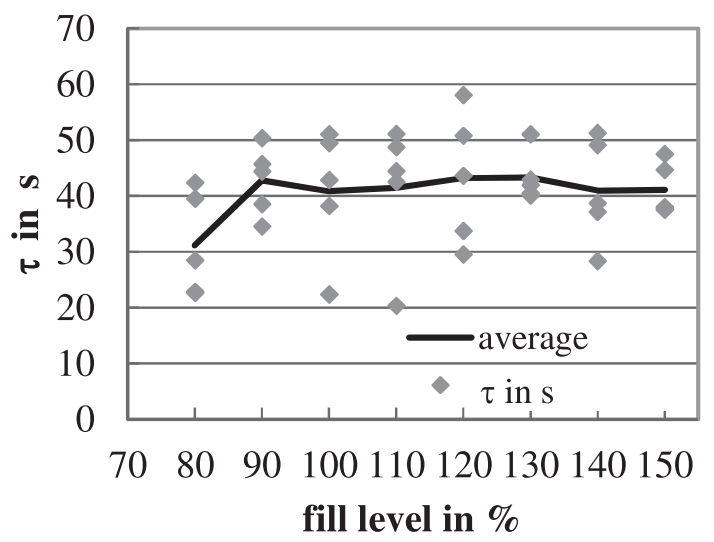

Fig. 8. Water model (scale 1:4) of a 120 t AOD converter; mixing time vs. fill level in \% of the nominal fill level (preliminary tests, pulse injection; 5 different tests per fill level).
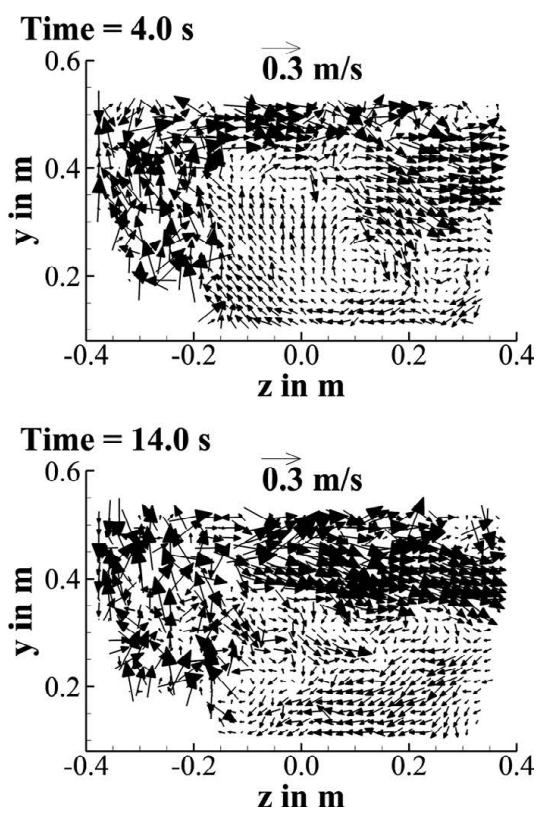

Fig. 9. PIV measurement in the water model ( $1: 4$ scale) of a $120 \mathrm{t}$ AOD converter, standard fill level $\left(\mathrm{H}_{\mathrm{f}} / \mathrm{D}_{1}=0.56\right)$, standard blowing rate $\left(\mathrm{Fr}_{\mathrm{m}}=923\right)$, transient velocity field in the symmetry plane. 


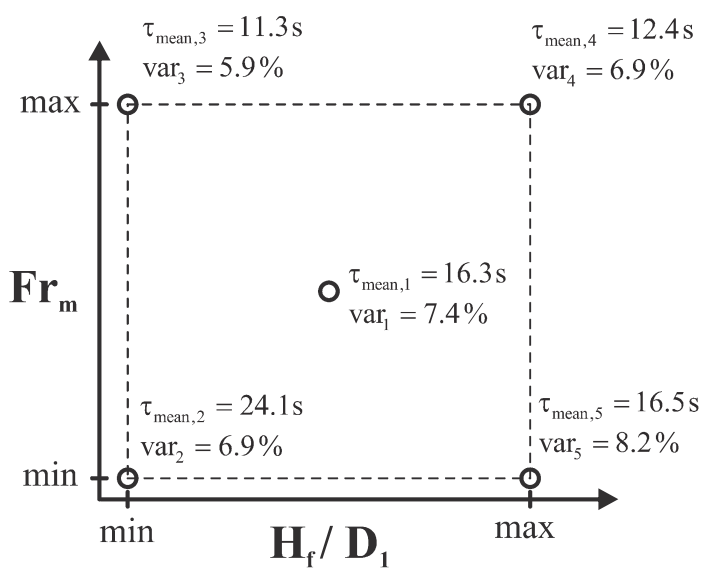

Fig. 10. Operating range and measurement points used for the applicability study of the presented technique to determine the average mixing time.

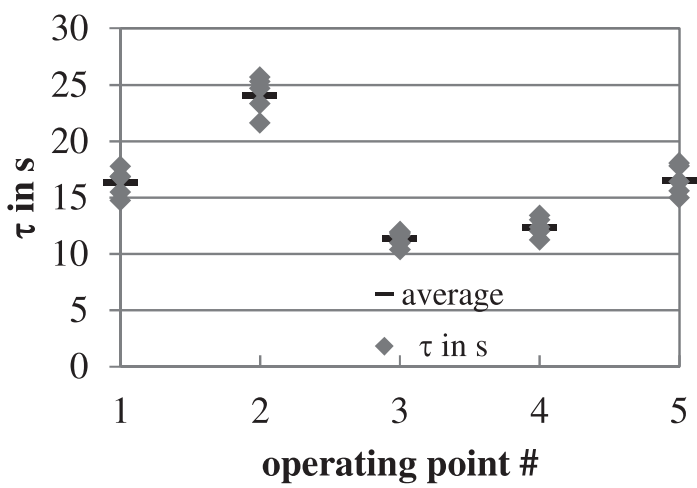

Fig. 11. Water model (scale 1:4) of a $120 \mathrm{t}$ AOD converter; mixing time for the tested operating points corresponding to the study of applicability (continuous injection; 5 different tests per operating point)

$24.1 \mathrm{~s}$ for the entire range of measurements. Compared to the preliminary experiments the variation is reduced remarkably (cf. Fig. 8.). The variations for the impulse coloring injection presented there are between $20 \%$ and $60 \%$. The presented tests show that the advanced method is able to calculate reproducible mixing times with low variations.

Comparing $\tau_{95 \%}$ and $\tau_{\text {mean }}$, the latter describes the time when the areas highlighted in grey in Fig. 7 have the same size. The time at the position where both areas intersect is $\tau_{\text {mean. }}$. The correlation between both mixing times has as yet not been evaluated. However, at this present time it can be pointed out, that $\tau_{\text {mean }}$ is a characteristic variable which describes the mixing behavior of the system. As shown before, due to the continuous tracer injection the variance obtained using $\tau_{\text {mean }}$ is remarkably reduced compared to the evaluation of mixing time using $\tau_{95 \%}$.

\subsection{Response Contour of Mixing Time}

As a design of experiments technique, LHS is used to define 50 measurement points within the operating range. Due to the fact that two parameters are varied $\left(\mathrm{Fr}_{\mathrm{m}}\right.$ and $\left.\mathrm{H}_{\mathrm{f}} / \mathrm{D}_{1}\right)$, a response contour plot of mixing time as a function of the modified Froude number and the height-to-diameter ratio can be calculated. A linear regression analysis is performed in order to obtain a mathematical relation between the input parameters and the average mixing time. The five operating points described in section 3.2 were added to the 50 data-
Table 4. $\mathrm{R}^{2}$-values of the evaluates fit models.

\begin{tabular}{cc}
\hline Model order & $\mathrm{R}^{2}$ \\
\hline Linear & 0.487 \\
Quadratic & 0.634 \\
Cubic & 0.757 \\
$4^{\text {th }}$-order & 0.771 \\
\hline
\end{tabular}

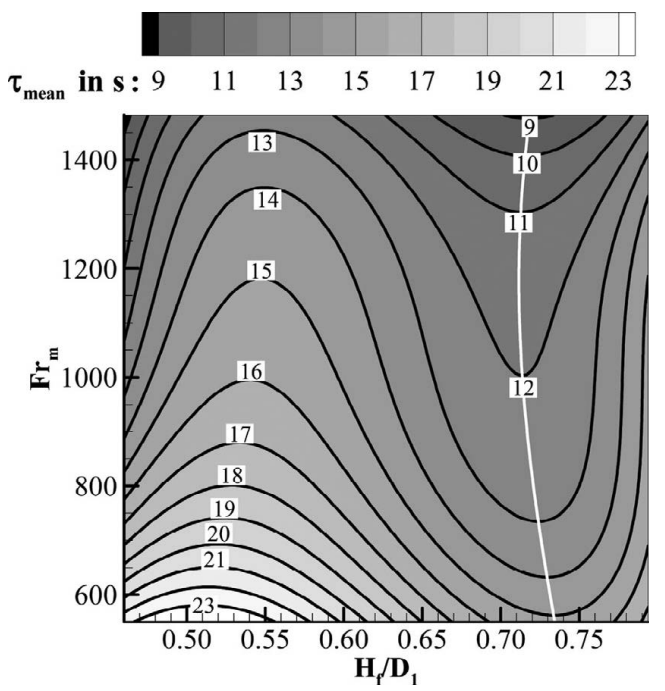

Fig. 12. Response contour plot of mixing time; $\tau_{\text {mean }}$ as a function of the modified Froude number $\left(\mathrm{Fr}_{\mathrm{m}}\right)$ and the height to diameter ratio $\left(\mathrm{H}_{\mathrm{f}} / \mathrm{D}_{1}\right)$.

sets. Thus, the total amount of 55 analyzed operating points is used in the regression analysis. Four polynomial models $\left(1^{\text {st }}\right.$ to $4^{\text {th }}$ order $)$ have been tested to achieve the best fit. The coefficients of determination $\left(\mathrm{R}^{2}\right.$-value) of the four tested models are shown in Table 4 . The $\mathrm{R}^{2}$-value of the $4^{\text {th }}$-ordermodel was just $2 \%$ better compared to the cubic model. To reduce the possibility of over-fitting and to keep the model as simple as possible the cubic model has been chosen to approximate the raw data. Equation (7) shows the regression formula for the cubic model.

$$
\begin{aligned}
\tau_{\text {mean }}\left(\kappa, \mathrm{Fr}_{\mathrm{m}}\right) & =\mathrm{b}_{0}+\mathrm{b}_{1} \cdot \kappa+\mathrm{b}_{2} \cdot \kappa^{2}+\mathrm{b}_{3} \cdot \kappa^{3}+\mathrm{b}_{4} \cdot \mathrm{Fr}_{\mathrm{m}}+\mathrm{b}_{5} \cdot \kappa \cdot \mathrm{Fr}_{\mathrm{m}} \\
& +\mathrm{b}_{6} \cdot \kappa^{2} \cdot \mathrm{Fr}_{\mathrm{m}}+\mathrm{b}_{7} \cdot \mathrm{Fr}_{\mathrm{m}}{ }^{2}+\mathrm{b}_{8} \cdot \kappa \cdot \mathrm{Fr}_{\mathrm{m}}{ }^{2}+\mathrm{b}_{9} \cdot \mathrm{Fr}_{\mathrm{m}}{ }^{3} \\
\text { with }: \kappa & =\left(\frac{\mathrm{H}_{\mathrm{f}}}{\mathrm{D}_{1}}\right)
\end{aligned}
$$

$$
\begin{array}{ll}
\mathrm{b}_{0}=-0.23 \mathrm{e}+03 \mathrm{~s} & \mathrm{~b}_{5}=-2.10 \mathrm{e}-01 \mathrm{~s} \\
\mathrm{~b}_{1}=1.61 \mathrm{e}+03 \mathrm{~s} & \mathrm{~b}_{6}=-5.78 \mathrm{e}-02 \mathrm{~s} \\
\mathrm{~b}_{2}=-2.81 \mathrm{e}+03 \mathrm{~s} & \mathrm{~b}_{7}=1.15 \mathrm{e}-04 \mathrm{~s} \\
\mathrm{~b}_{3}=1.52 \mathrm{e}+03 \mathrm{~s} & \mathrm{~b}_{8}=-5.43 \mathrm{e}-05 \mathrm{~s} \\
\mathrm{~b}_{4}=-2.01 \mathrm{e}-01 \mathrm{~s} & \mathrm{~b}_{9}=-2.48 \mathrm{e}-08 \mathrm{~s}
\end{array}
$$

Figure 12 shows the response contour plot obtained by means of the cubic model. Regarding the Froude number, there is a decrease in mixing time with higher Froude numbers and higher volume flow rates, respectively. This tendency is already described in the literature. ${ }^{7-12)}$ The tendency with respect to the $\mathrm{H}_{\mathrm{f}} / \mathrm{D}_{1}$-ratio (fill level) shows a channel-shaped minimum in the range of 0.70 and 0.75 , 
which appears for the entire range of investigated modified Froude numbers. The white line in Fig. 12 illustrates the local minima in the described region. This can be regarded as an optimal $\mathrm{H}_{\mathrm{f}} / \mathrm{D}_{1}$-ratio for the design of $\mathrm{AOD}$ vessels.

\section{Conclusions}

The mixing time in a water model of a side-blown AOD converter has been determined. A novel approach to determine the mixing time using a continuous tracer injection has been tested and evaluated. Food coloring is used as tracer. The mixing is quantified by absorption-photometer technique. The volume flow rate and the fill level are varied and their influence on mixing time is successfully evaluated.

(1) Food coloring is a reliable tracer for mixing time experiments in water models. Contrary to salt solutions there is no influence of the coloring density on the water flow. Thus, convection effects caused by the tracer can be neglected.

(2) The variances in mixing time obtained with continuous tracer injection are reduced remarkably compared to the impulse injection method. Furthermore, the described setup can be used in water models of any kind as well (EAF, BOF, Ladle).

(3) With increasing modified Froude number (increasing volume flow rate), the mixing time decreases.

(4) There is an obvious dependence of mixing time on the variation of the $\mathrm{H}_{\mathrm{f}} / \mathrm{D}_{1}$-ratio (fill level). The response contour plot shows a channel shaped minimum of mixing time in the range of $0.7<\mathrm{H}_{\mathrm{f}} / \mathrm{D}_{1}<0.75$. This can be regarded as an optimal $\mathrm{H}_{\mathrm{f}} / \mathrm{D}_{1}$-ratio for the design of the AOD water model. However, for the variation of the $\mathrm{H}_{\mathrm{f}} / \mathrm{D}_{1}$-ratio the fluid height $\mathrm{H}_{\mathrm{f}}$ was varied and $\mathrm{D}_{1}$ was given by the fixed geometry of the water model. Further investigations regarding a variable vessel diameter $\mathrm{D}_{1}$ would have to be carried out to prove the above mentioned hypothesis.

(5) The results can be used to validate numerical simulations of the mixing behavior in water models. In a further step, the numerical models can be adopted to be applied for an actual AOD process (steel/slag/gas). These simulations can then be used to prove whether the described minimum in mixing time in the range of $0.7<\mathrm{H}_{\mathrm{f}} / \mathrm{D}_{1}<0.75$ is independent of the investigated multiphase system. This task is the challenge to be addressed in future work.

\section{REFERENCES}

1) M.-Y. Zhu, I. Sawada and M. Iguchi: ISIJ Int., 38 (1998), 411.

2) R. Figueira and J. Szekely: Metall. Mater. Trans. B, 16 (1985), 67.

3) T. M. J. Fabritius, P. T. Mure and J. J. Härkki: ISIJ Int., 43 (2003), 1177.

4) A. Tilliander, T. L. I. Jonsson and P. G. Jönsson: ISIJ Int., 44 (2004), 326.

5) C. Wuppermann, A. Rückert, H. Pfeifer and H.-J. Odenthal: Proc. of Fachtagung "Lasermethoden in der Strömungsmesstechnik", Deutsche Gesellschaft für Laser-Anemometrie GALA e.V., Cottbus, (2010), 33.

6) H.-J. Odenthal, U. Thiedemann, U. Falkenreck and J. Schlüter: Metall. Mater. Trans. B, 41B (2010), 396.

7) J. H. Wei, J. C. Ma, Y. Y. Fan, N. W. Yu, S. L. Yang, S. H. Xiang and D. P. Zhu: Ironmaking Steelmaking, 26 (1999), 363.

8) J. H. Wei, J. C. Ma, Y. Y. Fan, N. W. Yu, S. L. Yang, S. H. Xiang and D. P. Zhu: Iron Steelmaker, 28 (2001), 59.

9) J. H. Wei, J. C. Ma, Y. Y. Fan, N. W. Yu, S. L. Yang, S. H. Xiang and D. P. Zhu: Proc. of 59th Ironmaking Conf., ISS, Warrendale, PA, (2000), 505

10) J.-H. Wei, H.-L. Zhu, H.-B. Chi and H.-J. Wang: ISIJ Int., 50 (2010), 26.

11) P. Ternstedt, A. Tilliander, P. G. Jönsson and M. Iguchi: ISIJ Int., 50 (2010), 663.

12) T. Fabritius, P. Kupari and J. Harkki: Scand. J. Metall., 30 (2001), 57.

13) R. Bölling: Dissertation, RWTH Aachen, (2003).

14) D. Bouchard, F. G. Hamel, S. F. Turcotte and J.-P. Nadeau: ISIJ Int., 41 (2001), 1465.

15) H. W. Emmons: Fundamentals of Gas Dynamics, Princeton University Press, Princeton, (1958).

16) M. Stein: Technometrics, 29 (1987), 143.

17) M. D. McKay, R. J. Beckman and W. J. Conover: Technometrics, 21 (1979), 239. 